\title{
Association of Asian Dust with daily medical consultations for pollinosis in Fukuoka City, Japan
}

\author{
Soyoko Sakata ${ }^{1 *}$, Shoko Konishi ${ }^{1,2}$, Chris Fook Sheng $\mathrm{Ng}^{3}$, Reiko Kishikawa ${ }^{4}$ and Chiho Watanabe
}

\begin{abstract}
Background: The objective is to examine the association between AD and the daily number of medical consultations for pollinosis in Fukuoka City.

Methods: We analyzed 65,488 daily medical consultations for pollinosis from 4 clinics in Fukuoka City from February to April, 1989-2012. Time-series analyses were performed to estimate the clinic-specific relative risk (RR) of clinical pollinosis associated with AD, adjusting for airborne pollen, suspended particulate matter (SPM), meteorological and temporal factors. Delayed effects were considered. The association with SPM was also examined given its relationship with AD. The clinic-specific RRs were combined using meta-analytic technique.

Results: AD on the same day (lag 0 ) and the previous 3 to 5 days (lags 3, 4, and 5) was positively associated with the risk of medical consultations for pollinosis. Clinic visits were 21.5\% (95\% confidence interval 3.1\% - 43.1\%) higher when there was an AD event (across lags 0-5). The association with SPM showed comparable lag structure, but with smaller effect estimates. When stratified by the occurrence of AD, the estimated risk increases associated with SPM did not differ between the AD-affected and AD-free days.
\end{abstract}

Conclusion: $A D$ is associated with an increased risk of medical consultations for pollinosis in spring. More research is needed to elucidate the roles of air particles with different sizes.

Keywords: Asian Dust, Particulate matter, Pollen, Pollinosis, Air pollution

\section{Background}

Asian Dust (AD) is a meteorological event that affects Japan especially in the spring when dusts are transported eastward via airstreams from the deserts of China and Mongolia. A number of studies have suggested that AD can adversely impact human health. Specifically, earlier research has linked AD to an increased risk of all-cause $[1-4]$, cardiovascular $[1,5,6]$, cerebrovascular [3] and respiratory mortality $[7,8]$. Several studies have also indicated that the risk of hospitalization for respiratory $[9,10]$, cerebrovascular [11] and cardiovascular diseases $[10,12]$ may increase on $\mathrm{AD}$ days.

There is some evidence that $\mathrm{AD}$ may also contribute to the worsening of allergic disease symptoms [13-15],

\footnotetext{
*Correspondence: soyoko.sakata@gmail.com

'Department of Human Ecology, Graduate School of Medicine, The

University of Tokyo, 7-3-1 Hongo, Bunkyo-ku, Tokyo 113-0033, Japan

Full list of author information is available at the end of the article
}

although this association has not been consistently observed in previous studies [16-18]. In Japan, severe $\mathrm{AD}$ events have been found to be associated with an increased risk of hospitalization for asthma [13] and aggravated lower respiratory symptoms [14]. On the other hand, a study using data from Fukuoka in Kyushu Japan showed that the odds of asthma hospitalization among children for a $10 \mu \mathrm{g} / \mathrm{m}^{3}$ increase in SPM did not differ between the $\mathrm{AD}$ and non- $\mathrm{AD}$ days, suggesting a lack of association between children asthma hospitalization and $\mathrm{AD}$ events [16]. Non-significant associations have also been reported in a study of daily asthmatic admissions in Taipei [17] and daily clinical consultations for conjunctivitis in the same location [18].

To our best knowledge, no previous study has examined if $\mathrm{AD}$ might potentially contribute to an increase in the number of medical consultations for pollinosis. This is an important research gap, especially since there have been a 
few small-size studies ( $n=23$ to 54 ) which indicated that allergic symptoms such as allergic rhinitis - a main symptom of pollinosis - might be aggravated by AD [19-21]. For example, a cross-sectional study has suggested that $\mathrm{AD}$ might act as an adjuvant in promoting allergic rhinoconjunctivitis induced by the inhalation of allergens such as pollens and fungi [19]. Another study has reported that nasal and ocular allergic symptoms are associated with $\mathrm{AD}$ before and after the Japanese cedar pollen season, but not during [20]. The worsening of nasopharyngeal, ocular, respiratory, and skin allergic symptoms have also been observed on AD event days in a study in Yonago, a city facing the Sea of Japan [21].

The objective of the current study is to examine the association between airborne $\mathrm{AD}$ and the daily number of medical consultations for pollinosis. We used data from Fukuoka City, which is located in the Kyushu region of Japan close to the Eurasian continent with frequent experiences of $\mathrm{AD}$ events in the spring (Fig. 1). The associations of health problems, such as asthmatic symptoms and ischemic stroke with $\mathrm{AD}$ have been previously investigated in this location [16, 22]. In the past, some studies have relied on $\mathrm{PM}_{10} / \mathrm{PM}_{2.5}$ to ascertain the occurrence of $\mathrm{AD}[1,17,18,23]$. However, recently it has been proposed that $\mathrm{AD}$ may serve as an aid to enhance allergic reactions independent of particulate matter [13-15, 19-21]. Hence, in the present study, an AD event was defined based on the criteria set by the Japan Meteorological Agency, i.e., when any of the air monitoring stations located in Fukuoka City reported a turbid atmosphere, i.e., visibility $<10 \mathrm{~km}$, or when $\mathrm{AD}$ particles are visible via remote sensing or sun photometer. We also included the suspended particulate matter (SPM) in the current study in view of its relationship with AD (i.e. higher SPM level on $\mathrm{AD}$ days) [16], and controlled for airborne pollen level as the main trigger of pollinosis in all analyses. Assuming that the exacerbation of pollinosis symptoms by atmospheric environment is reflected in the daily number of medical consultation for pollinosis [24], we analyzed data comprising 24 years of daily consultations for pollinosis and the environmental factors (i.e. AD and SPM) in Fukuoka City using time series regression.

\section{Methods \\ Clinic visit data}

Data on the daily number of consultations for pollinosis at 4 otorhinolaryngology clinics (referred to as Clinic I, II, III, and IV) in Fukuoka City, Japan were obtained from the database organized by the Fukuoka Prefecture Medical Association and the Fukuoka Prefecture Medical Center [25] (Fig. 2). From 13 clinics listed in the database these 4 clinics were selected based on their availability of the daily consultation data and their proximity to where the airborne pollen and air pollutants were measured. The database contains the daily number of medical consultations for pollinosis at each clinic and contains no personal identifiable information of patients. Pollinosis cases were diagnosed according to the clinical practice guidelines for allergic rhinitis at each clinic [26]. The period of data varied by clinic: 1989 to 2012 for Clinic I and III, 1994 to 2012 for Clinic II, and 1989 to 2001 for Clinic IV.

\section{Pollen data}

Daily measurements of airborne pollen were obtained from the National Hospital Organization Fukuoka Hospital in Fukuoka City (Fig. 2). The ambient concentrations of pollen from Cryptomeria japonica (Japanese cedar

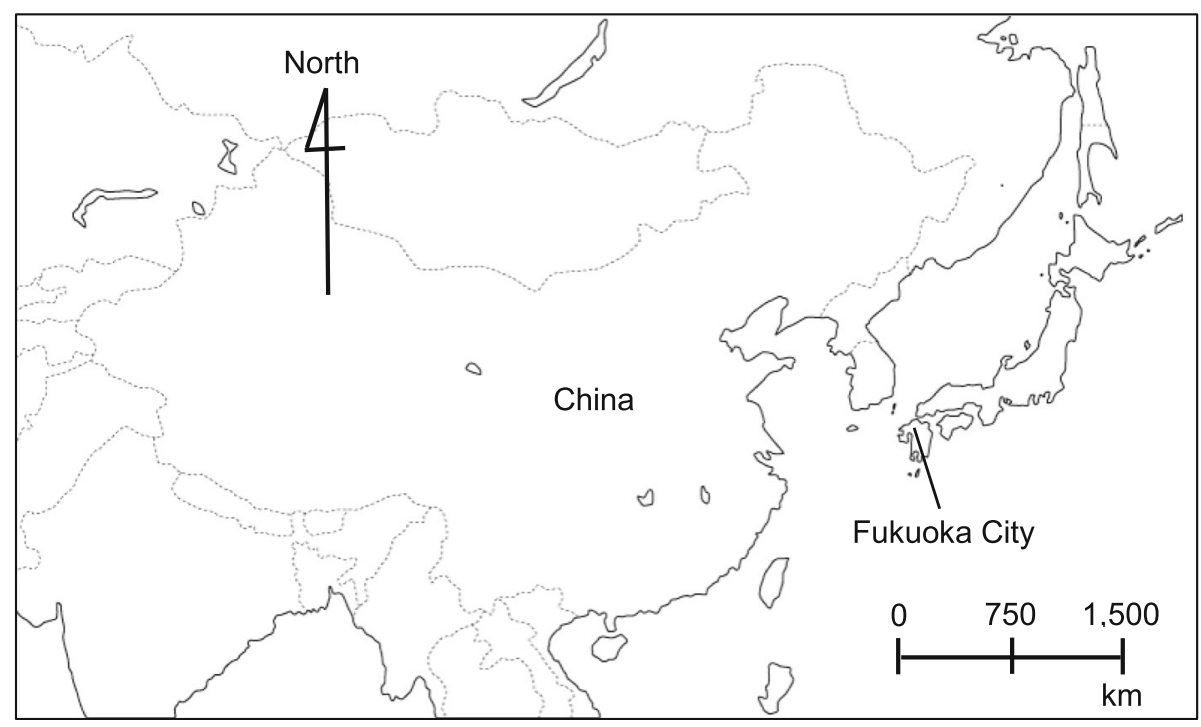

Fig. 1 Location of Fukuoka City in East Asia 


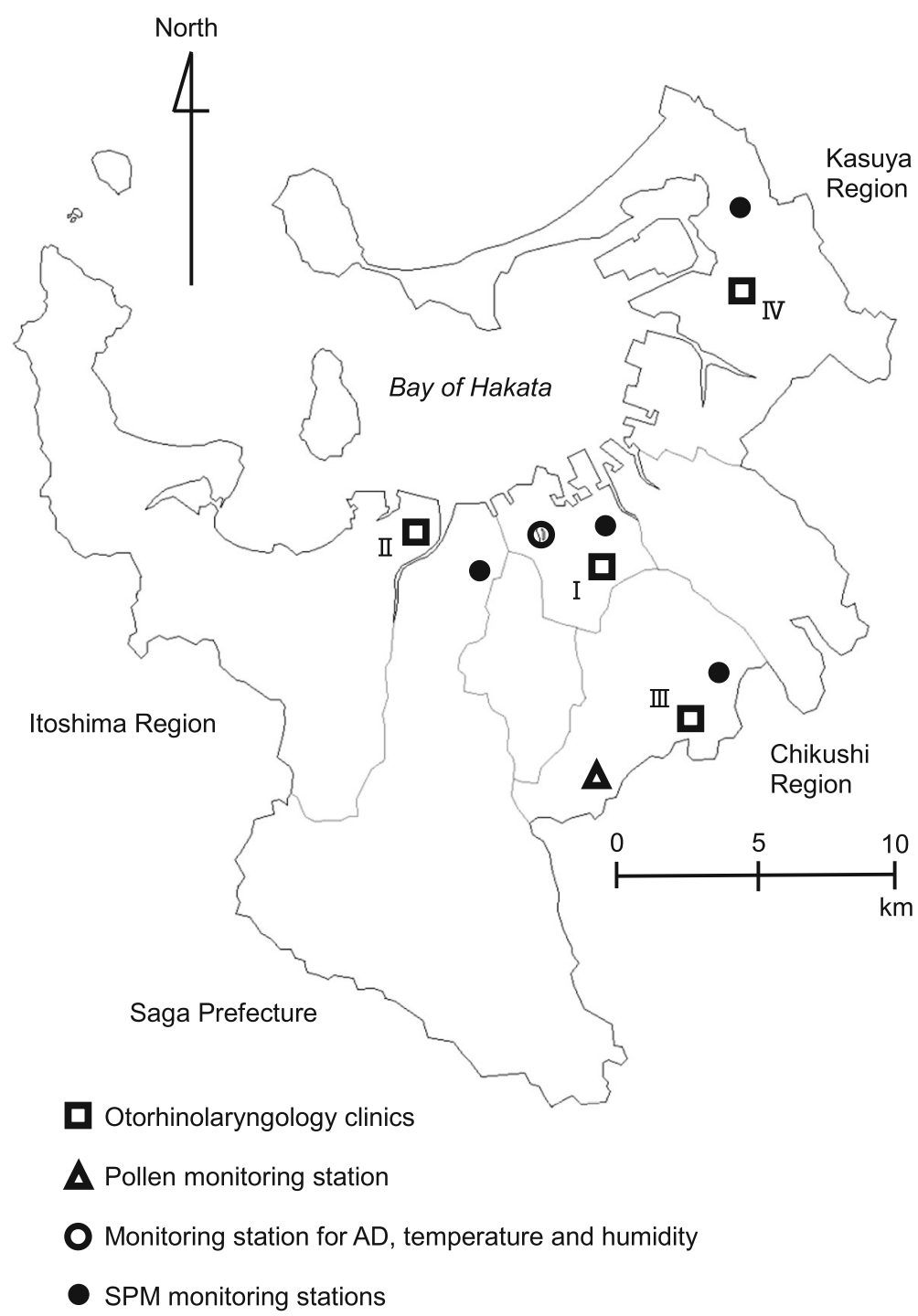

Fig. 2 Fukuoka City and the location of the otorhinolaryngology clinics and monitoring stations for air pollen, AD, SPM and weather variables

or sugi in Japanese) and Chamaecyparis obtusa (Japanese cypress or hinoki in Japanese) were determined using the Durham technique [27], whereby the airborne pollen grains were captured on a vaseline coated glass slide fixed inside a Durham sampler. Pollen grains on the glass slide were then stained with fuchsin and counted. The slides were changed every day except on weekends where they were left for 2 to 3 days before retrieval. For the analysis, the 2- or 3-day averages were computed for pollen counts on weekends (e.g., the same values for Friday, Saturday, and Sunday if only a single pollen count was provided for a particular weekend). We combined sugi and hinoki pollen counts in the analysis as both are known to induce pollinosis from February to April [26]. The pollen data used in the analysis were cubic root transformed in order to improve the normality of its distribution.

\section{Environmental data}

We obtained the AD data from the Japan Meteorological Agency (JMA). AD was monitored daily at the Fukuoka District Meteorological Observatory in Fukuoka City and recorded as either present or absent based on visual observation that took place at the observatory (Fig. 2) at random time every day. The JMA defines AD day based on a visibility criterion of $<10 \mathrm{~km}$ as well as the information from sun photometer or satellites [28].

For air pollution data, continuous air quality monitoring stations were identified based on their proximity to the clinics (Fig. 2). We extracted the hourly concentrations of SPM from a database provided by the National Institute for Environmental Studies, Japan. SPM is defined as particle with aerodynamic diameter of less than $10 \mu \mathrm{m}$ at $100 \%$ efficiency cut-off [29]. The theoretical 50\% cut-off 
diameter for SPM is assumed to be approximately $7 \mu \mathrm{m}$ [29]. We computed the daily mean concentration of SPM from the hourly data provided when there were no more than 5 missing hourly values per day. The daily SPM levels were highly correlated among the stations, with correlation coefficients ranging between 0.80 and 0.89 . The daily values from the 4 stations were therefore averaged for analysis.

Data on daily mean temperature $\left({ }^{\circ} \mathrm{C}\right)$ and relative humidity (\%) measured continuously at Chuo-ku, Fukuoka City was also obtained from the JMA for confounding adjustment.

\section{Statistical analysis}

We analyzed data from February to April using a generalized linear model with quasi-Poisson link to account for overdispersion in the outcome - the daily number of clinic visits for pollinosis. The exposure variables were the presence/absence of $\mathrm{AD}$ and the daily mean concentrations of SPM. Other variables included in the model were the day of the week (indicator denoting Monday to Sunday), public holidays (yes/no), month (indicator for January to December), year indicator, pollen (average of lags $0-5$, i.e., mean concentration on the current and 5 previous days) and the natural cubic splines of daily mean temperature and relative humidity with $3^{\circ}$ of freedom. The choice of the 5 -days delayed effects of pollen was based on findings from a previous study in Tokyo [24].

We computed the relative risk (RR) and the corresponding 95\% confidence intervals (CI) for the association between the daily consultations for pollinosis and the occurrence of $\mathrm{AD}$ for each clinic using single- and bi-pollutant models with the addition of SPM. Both models included a term for the interaction between AD and pollen. The bi-pollutant models additionally accounted for the interaction between AD and SPM, and they provide SPM-adjusted effect estimates of AD, which allow further examination of the AD-pollinosis association excluding the portion attributable to SPM. We examined the single-day delayed effects of $\mathrm{AD}$ from lag 0 (current day) to lag 6 one at a time (because of correlated lag terms). We then computed the cumulative effects using exposure information up to the previous 5 days (i.e. combining the indicators across lags $0-5$ and excluding lag 6 where the association began to attenuate). To examine the association between SPM and AD days, the effect of SPM was estimated in the same manner stratified by AD-affected or AD-free days, with consideration for the interaction between SPM and pollen. The statistical difference of the estimates for the effects of SPM on AD-affected days and AD-free days was tested using the confidence interval method [30].
To obtain an average effect of AD or SPM for the study location, we pooled the clinic-specific estimates using a random effects model. The RR estimates for the effects of SPM correspond to a $10 \mu \mathrm{g} / \mathrm{m}^{3}$ increase in the mean concentration of the pollutant. Confidence intervals that exclude 1 indicate statistically significant effect estimates. We performed all analyses in $\mathrm{R}$ (version 2.15.3; $\mathrm{R}$ Project for Statistical Computing, Vienna, Austria). The level of statistical significance was set at $p<0.05$.

\section{Results}

AD was observed on 238 (6.6\%) of the 3630 days included in the study. $\mathrm{AD}$ occurred with a median value of 7 days per year between February and April. A total of 65,488 clinic visits for pollinosis were analyzed. Across the 4 clinics, there were 9.2 visits per day during the 3-months period. The frequency of visits did not differ statistically between $\mathrm{AD}$-affected and $\mathrm{AD}$-free days (Table 1). The level of SPM was significantly higher when AD was present, while the concentration of pollen was only marginally higher. Temperature and relative humidity differed significantly based on the presence of AD.

$\mathrm{AD}$ was associated with increased risk of clinic visits for pollinosis at lag 0 (pooled $R R=1.175,95 \% \mathrm{CI}$ 1.061-1.301, Table 2). The estimated risk increased gradually until lag 4 , with lags 3 to 5 being statistically significant before attenuation at lag 6. The 6-days cumulative RR (lags 0-5) was 1.215 (95\% CI 1.031-1.431). In the bi-pollutant model, the estimated RR for the effect of AD increased slightly when SPM was added to the model. The estimated effects of SPM and its interaction with AD were small and generally insignificant (Table 2 and Additional file 1: Table S1).

To further examine the effect of SPM given the higher concentration during the AD events, we stratified the effect of SPM into AD-affected and AD-free days (Table 3). The estimated 6-days cumulative effect of SPM (lag 0-5) was slightly larger on $\mathrm{AD}$-affected days than on $\mathrm{AD}$-free days $(R R=1.066,95 \%$ CI $1.007-1.127$ vs. $R R=1.062$, 95\% CI 1.022-1.104), although the difference was not statistically significant. When Clinic IV was excluded because of the shorter study period, the difference remained statistically insignificant. The estimated effects of SPM were delayed for approximately 5 days and attenuated at lag 6 on both the $\mathrm{AD}$-affected and $\mathrm{AD}$-free days (Table 3). The breakdown by clinic is presented in Additional file 2: Table S2.

\section{Discussion}

Findings of the current study suggest for the first time that $\mathrm{AD}$ is associated with an increased number of daily medical consultations for pollinosis in Japan. The number of consultations increased by approximately $21.5 \%$ (95\%CI $3.1 \%-43.1 \%)$ on average across the four clinics 
Table 1 Summary statistics for daily clinic consultations, concentrations of SPM, airborne pollen and meteorological variables by the presence of $A D$

\begin{tabular}{|c|c|c|c|}
\hline & $\begin{array}{l}\text { AD-affected } \\
\text { days }\end{array}$ & $\begin{array}{l}\text { AD-free } \\
\text { days }\end{array}$ & $\begin{array}{l}P \text {-value for } \\
\text { difference }\end{array}$ \\
\hline Total number of days & 238 & 3392 & \\
\hline Median (range) per year & $7(1,26)$ & $82(63,89)$ & \\
\hline \multicolumn{4}{|c|}{ Clinic consultation [mean (SD)] } \\
\hline Clinic I & $8.4(9.9)$ & $8.7(10.4)$ & 0.65 \\
\hline Clinic II & $7.7(8.7)$ & $8.8(9.0)$ & 0.14 \\
\hline Clinic III & $11.9(12.4)$ & $12.3(13.3)$ & 0.73 \\
\hline Clinic IV & $4.6(7.0)$ & $5.2(6.8)$ & 0.39 \\
\hline \multicolumn{4}{|l|}{$\operatorname{SPM}\left(\mu \mathrm{g} / \mathrm{m}^{3}\right)$} \\
\hline Mean (SD) & $58.9(32.2)$ & $29.4(13.4)$ & $<0.01$ \\
\hline Median (IQR) & $52.7(40.2,67.6)$ & $26.8(19.8,36.0)$ & \\
\hline 10th, 90th centile & $28.6,88.3$ & $15.3,47.1$ & \\
\hline Days missing (\%) ${ }^{\mathrm{a}}$ & $10(1.5)$ & $174(2.7)$ & \\
\hline \multicolumn{4}{|l|}{ Pollen (grain/ $\mathrm{cm}^{2}$ ) } \\
\hline Mean (SD) & $45.5(110.4)$ & $30.1(77.2)$ & 0.06 \\
\hline Median (IQR) & $3.5(0.8,23.1)$ & $3.0(0.5,18.5)$ & \\
\hline 10th, 90th centile & 0,153 & 0,90 & \\
\hline Days missing $(\%)^{a}$ & $0(0)$ & $53(0.8)$ & \\
\hline \multicolumn{4}{|l|}{ Temperature $\left({ }^{\circ} \mathrm{C}\right)$} \\
\hline Mean (SD) & $13.9(3.2)$ & $11.0(4.2)$ & $<0.01$ \\
\hline \multicolumn{4}{|l|}{ Relative humidity (\%) } \\
\hline Mean (SD) & $58.3(10.7)$ & $63.5(13.1)$ & $<0.01$ \\
\hline
\end{tabular}

$A D$ Asian dust, SPM suspended particulate matter, SD standard deviation, IQR interquartile range

${ }^{a}$ Total for four clinics

when there was an $\mathrm{AD}$ event (Table 2). The association was short-term beginning immediately at lag 0 (i.e. on the same day) and observed up to the previous 5 days. When SPM was included as adjustment, the estimates of AD effect remained significant (but they increased slightly likely because of collinearity). We did not find evidence of interaction between AD and SPM (Additional file 1: Table S1), despite the higher SPM level on AD days. The results of further analysis showed that SPM was associated with the daily consultations for pollinosis, with a lag structure that was fairly similar to that of AD (Table 3 ). The estimated effects of SPM were smaller than those for AD, and they did not differ between the $\mathrm{AD}$ and non-AD days, which has also been reported in a study of asthma admission among children and AD in the same location [16].

There are two possible ways AD might be linked to the exacerbation of pollinosis symptoms, which might in turn leads to an increase in the number of consultations. First, AD may act as an adjuvant for allergens [31]. AD particles contain soil-derived metals, anthropogenic metals, and other forms of atmospheric pollutants by human activity, and then act to promote nasal and ocular symptoms [31]. Second, AD components may contain bacteria, fungi and viruses, all of which can have a direct effect as allergens [3, 19, 32]. For example, earlier research has suggested that desert dust may contain fungi which are allergenic, [33], and that airborne bacteria may increase by approximately 4 times on $\mathrm{AD}$ days compared with non-AD days [32]. It has been suggested that these microorganisms may negatively affect the human immune system and exacerbate pollinosis symptoms [33, 34].

We observed a delay of less than a week (i.e. until lag 5) in the association between $\mathrm{AD}$ and the daily consultations for pollinosis in this study. This delayed effect was noted in all the clinics except Clinic II (Table 2). A possible explanation is that some patients were likely not able to visit the clinics on the same day when their symptoms became worse, and their visits later were registered as a lag effect [16]. It is also possible that the transported dust remains in the air for several days after an $A D$ event even if it is not observed visually, although further investigation is required to understand this phenomenon, particularly the role of long-range fine/ultrafine particles that can remain suspended in the air for a longer period.

In this study, we examined the effect of $\mathrm{AD}$ defined based on meteorological conditions instead of the level of SPM. This allows us to examine the total effect of $\mathrm{AD}$, which may encompass contribution by factors unrelated to SPM (e.g., microorganism-related AD factor described above). Our results showed that the effect estimates for AD remained significant after adjusting for SPM, implying there might be other air pollutants or unmeasured exposures that might have triggered or worsened the pollinosis symptoms on AD days. Besides the microscopic organisms, a likely explanation would be that $\mathrm{AD}$ might also represent smaller inhalable particles such as fine particulate matter $\left(\mathrm{PM}_{2.5}\right)$. It has been previously suggested that the aeroallergens from pollens might be able to bind to small air particles [35], and in Japan, a study has indicated that particles as fine as $0.3 \mu \mathrm{m}$ might contain allergens such as Cry $\mathrm{j} 1$ and Cry $\mathrm{j} 2$ from the Japanese cedar pollens [36]. In addition, a recent study has indicated that the synergetic effect between airborne pollen and $\mathrm{PM}_{2.5}$ was stronger and more robust than the interaction between pollen and SPM [24]. Nevertheless, because the measurements of $\mathrm{PM}_{2.5}$ were not available for most of the study period (the data was only available since 2010), we were unable to examine this in the context of $\mathrm{AD}$ and pollinosis consultations. Future studies are therefore needed to explore the roles of air particles of different size, including their origin (e.g. transported or local), chemical constituents, and potential interactions with airborne pollen concentrations during the spring season.

This study has several limitations. First, we had no information on age, sex and individual exposure or about the 
Table 2 Relative risks ${ }^{a}$ and 95\% confidence intervals for daily medical consultations for pollinosis in association with exposure to AD

\begin{tabular}{|c|c|c|c|c|c|c|c|}
\hline \multirow[t]{2}{*}{ Lag period for $A D$} & \multicolumn{3}{|c|}{$\begin{array}{l}\text { AD only } \\
\text { (Single-pollutant model) }\end{array}$} & \multicolumn{4}{|c|}{$\begin{array}{l}\text { AD with SPM }{ }^{\mathrm{b}} \\
\text { (Bi-pollutant model) }\end{array}$} \\
\hline & \multirow[t]{2}{*}{$\overline{R^{c}}$} & \multicolumn{2}{|l|}{$95 \% \mathrm{Cl}$} & \multirow[t]{2}{*}{$\overline{R^{c}}$} & \multicolumn{2}{|l|}{$95 \% \mathrm{Cl}$} & \multirow[t]{2}{*}{$P$-value for $\mathrm{AD} \times \mathrm{SPM}$} \\
\hline Clinic I $(n=18571)$ & & & & & & & \\
\hline Lag 0 & 1.215 & 1.003 & 1.472 & 1.383 & 1.046 & 1.828 & 0.43 \\
\hline Lag 1 & 1.353 & 1.116 & 1.640 & 1.814 & 1.348 & 2.442 & 0.05 \\
\hline $\operatorname{Lag} 2$ & 1.284 & 1.053 & 1.566 & 1.850 & 1.361 & 2.516 & 0.01 \\
\hline Lag 3 & 1.362 & 1.130 & 1.642 & 1.628 & 1.201 & 2.206 & 0.31 \\
\hline $\operatorname{Lag} 4$ & 1.404 & 1.160 & 1.700 & 1.897 & 1.406 & 2.559 & 0.05 \\
\hline $\operatorname{Lag} 5$ & 1.211 & 0.991 & 1.479 & 1.707 & 1.250 & 2.331 & 0.01 \\
\hline $\operatorname{Lag} 6$ & 1.315 & 1.078 & 1.605 & 1.814 & 1.353 & 2.433 & $>0.01$ \\
\hline Lags 0-5 & 1.241 & 1.095 & 1.407 & 1.440 & 1.175 & 1.766 & 0.31 \\
\hline \multicolumn{8}{|l|}{ Clinic II $(n=14741)$} \\
\hline Lag 0 & 1.344 & 1.316 & 1.373 & 1.107 & 0.863 & 1.421 & 0.70 \\
\hline Lag 1 & 0.948 & 0.779 & 1.155 & 1.022 & 0.762 & 1.370 & 0.93 \\
\hline $\operatorname{Lag} 2$ & 0.925 & 0.765 & 1.118 & 1.011 & 0.759 & 1.346 & 0.67 \\
\hline Lag 3 & 1.080 & 0.905 & 1.288 & 1.222 & 0.917 & 1.629 & 0.57 \\
\hline $\operatorname{Lag} 4$ & 1.082 & 0.905 & 1.293 & 1.207 & 0.908 & 1.605 & 0.57 \\
\hline Lag 5 & 1.067 & 0.889 & 1.280 & 1.122 & 0.851 & 1.479 & 0.77 \\
\hline $\operatorname{Lag} 6$ & 0.890 & 0.739 & 1.072 & 1.001 & 0.770 & 1.301 & 0.21 \\
\hline Lags $0-5$ & 1.029 & 0.919 & 1.152 & 1.120 & 0.933 & 1.345 & 0.62 \\
\hline \multicolumn{8}{|l|}{ Clinic III $(n=26186)$} \\
\hline Lag 0 & 1.177 & 0.993 & 1.394 & 1.119 & 0.879 & 1.426 & 0.37 \\
\hline Lag 1 & 1.126 & 0.944 & 1.344 & 1.049 & 0.804 & 1.370 & 0.37 \\
\hline $\operatorname{Lag} 2$ & 1.214 & 1.019 & 1.445 & 1.196 & 0.916 & 1.560 & 0.82 \\
\hline $\operatorname{Lag} 3$ & 1.276 & 1.079 & 1.509 & 1.273 & 0.971 & 1.669 & 0.75 \\
\hline $\operatorname{Lag} 4$ & 1.241 & 1.047 & 1.470 & 1.200 & 0.923 & 1.559 & 0.47 \\
\hline $\operatorname{Lag} 5$ & 1.192 & 1.005 & 1.415 & 1.151 & 0.891 & 1.488 & 0.53 \\
\hline $\operatorname{Lag} 6$ & 1.142 & 0.961 & 1.358 & 1.179 & 0.922 & 1.509 & 0.78 \\
\hline Lags $0-5$ & 1.147 & 1.025 & 1.283 & 1.167 & 0.975 & 1.397 & 0.90 \\
\hline \multicolumn{8}{|l|}{ Clinic IV $(n=5990)$} \\
\hline Lag 0 & 1.506 & 1.101 & 2.060 & 1.442 & 0.891 & 2.332 & 0.83 \\
\hline Lag 1 & 1.734 & 1.288 & 2.334 & 2.177 & 1.342 & 3.533 & 0.25 \\
\hline $\operatorname{Lag} 2$ & 1.769 & 1.286 & 2.434 & 2.299 & 1.384 & 3.820 & 0.16 \\
\hline Lag 3 & 1.668 & 1.216 & 2.288 & 1.820 & 1.090 & 3.038 & 0.58 \\
\hline $\operatorname{Lag} 4$ & 1.761 & 1.275 & 2.430 & 1.646 & 1.002 & 2.706 & 0.80 \\
\hline $\operatorname{Lag} 5$ & 1.181 & 0.851 & 1.639 & 1.244 & 0.748 & 2.069 & 0.76 \\
\hline $\operatorname{Lag} 6$ & 1.364 & 0.980 & 1.899 & 1.655 & 0.999 & 2.741 & 0.27 \\
\hline Lags $0-5$ & 1.594 & 1.283 & 1.980 & 2.024 & 1.408 & 2.910 & 0.07 \\
\hline \multicolumn{8}{|l|}{ Pooled estimates } \\
\hline Lag 0 & 1.175 & 1.061 & 1.301 & 1.203 & 1.045 & 1.385 & - \\
\hline Lag 1 & 1.238 & 0.976 & 1.570 & 1.395 & 0.970 & 2.006 & - \\
\hline $\operatorname{Lag} 2$ & 1.238 & 0.972 & 1.576 & 1.456 & 1.021 & 2.075 & - \\
\hline Lag 3 & 1.290 & 1.111 & 1.497 & 1.391 & 1.184 & 1.634 & - \\
\hline Lag 4 & 1.309 & 1.099 & 1.559 & 1.427 & 1.122 & 1.816 & - \\
\hline
\end{tabular}


Table 2 Relative risks ${ }^{a}$ and 95\% confidence intervals for daily medical consultations for pollinosis in association with exposure to AD (Continued)

\begin{tabular}{llllllll}
\hline Lag 5 & 1.156 & 1.045 & 1.279 & 1.278 & 1.039 & 1.572 & - \\
Lag 6 & 1.142 & 0.943 & 1.383 & 1.337 & 1.006 & 1.777 & - \\
Lags 0-5 & 1.215 & 1.031 & 1.431 & 1.348 & 1.075 & 1.690 & - \\
\hline
\end{tabular}

$A D$ Asian dust, SPM suspended particulate matter, $R R$ relative risk, $\mathrm{Cl}$ confidence interval

${ }^{a}$ Using single-lag model with adjustment for the day of the week, public holidays, month, year, pollen (average lag 0-5), interaction between AD-pollen and the natural cubic splines of daily mean temperature and relative humidity with $3^{\circ}$ of freedom

${ }^{\mathrm{b}}$ Additional adjustment for SPM (average lags $0-5$ ) and the corresponding interaction between AD-SPM; refer to Additional file 1: Table S1 for further information

${ }^{\mathrm{C}}$ Reference: AD-free days

participants' pollinosis history or history of other allergic diseases. The association between the daily number of medical consultations and AD might differ across such individual characteristics. Second, it was not possible to separate the first clinic visits from re-visits in the same year. First visit refers to the first examination that occurs when a patient start to experience pollinosis symptoms in each pollen season, while re-visits are usually re-examinations for the purpose of medicine refill. In the present study, as data with separate first and re-visits were not available, it is possible the association between air pollen and clinic visits for pollinosis might have been underestimated, leading to incorrect estimates for AD and SPM. For example, two previous studies that used data from a clinic in Tokyo reported that the positive correlation between the pollen count and the number of first examinations for pollinosis was stronger than that for re-examinations [34, 37], suggesting that the first visits might better reflect the

Table 3 Pooled estimates for the relative risk ${ }^{\mathrm{a}}$ with 95\% confidence intervals of daily medical consultations for pollinosis in association with a $10-\mu \mathrm{g} / \mathrm{m}^{3}$ increase in mean suspended particulate matter, by the presence of $A D$

\begin{tabular}{|c|c|c|c|c|c|c|c|}
\hline \multirow[t]{2}{*}{$\begin{array}{l}\text { Lag period } \\
\text { for } \mathrm{SPM}^{\mathrm{b}}\end{array}$} & \multicolumn{3}{|c|}{$\begin{array}{l}\text { (A) } \\
\text { AD-affected days }\end{array}$} & \multicolumn{3}{|c|}{$\begin{array}{l}\text { (B) } \\
\text { AD-free days }\end{array}$} & \multirow[t]{2}{*}{$\begin{array}{l}P \text {-value for } \\
(A)-(B)\end{array}$} \\
\hline & $\overline{R R}$ & $95 \% \mathrm{C}$ & & $\overline{\mathrm{RR}}$ & $95 \% \mathrm{C}$ & & \\
\hline Lag 0 & 0.972 & 0.931 & 1.015 & 1.004 & 0.983 & 1.025 & 0.19 \\
\hline Lag 1 & 1.000 & 0.963 & 1.039 & 1.005 & 0.986 & 1.025 & 0.84 \\
\hline $\operatorname{Lag} 2$ & 1.032 & 0.996 & 1.070 & 1.017 & 0.998 & 1.037 & 0.49 \\
\hline Lag 3 & 1.028 & 0.988 & 1.071 & 1.038 & 1.018 & 1.059 & 0.69 \\
\hline $\operatorname{Lag} 4$ & 1.038 & 1.001 & 1.076 & 1.026 & 1.010 & 1.042 & 0.58 \\
\hline Lag 5 & 1.060 & 1.011 & 1.111 & 1.023 & 1.007 & 1.038 & 0.15 \\
\hline $\operatorname{Lag} 6$ & 0.999 & 0.942 & 1.060 & 1.014 & 0.993 & 1.035 & 0.66 \\
\hline \multicolumn{8}{|l|}{ Lags $0-5$} \\
\hline All clinics & 1.066 & 1.007 & 1.127 & 1.062 & 1.022 & 1.104 & 0.94 \\
\hline Except Clinic IV & 1.071 & 1.011 & 1.135 & 1.055 & 1.014 & 1.097 & 0.68 \\
\hline
\end{tabular}

$A D$ Asian Dust, SPM suspended particulate matter, $R R$ relative risk, $C l$ confidence interval

a Using single-lag model with adjustment for the day of the week, public holidays, month, year, the natural cubic splines of daily mean temperature, relative humidity and pollen (lag $0-5$ ) with $3^{\circ}$ of freedom. An interaction term between SPM and pollen concentration was included. Refer to Additional file 2: Table S2 for further information

${ }^{\mathrm{b}}$ Delayed effects longer than 1 day were constrained as average severity of pollinosis symptoms. Third, this study did not consider other criteria air pollutants such as sulfur dioxide, nitrogen dioxide and ozone, which require further investigations as there have been evidence linking air pollution and the prevalence of allergic rhinitis [38, 39].

\section{Conclusions}

$\mathrm{AD}$ is positively associated with the daily number of medical consultations for pollinosis in the spring season. The increase in risk began on the day of $\mathrm{AD}$ and was attenuated within a week. The underlying mechanisms through which $\mathrm{AD}$ exacerbates the symptoms of pollinosis should be examined in future research.

\section{Additional file}

Additional file 1: Table S1. Regression ${ }^{\text {a }}$ coefficients (beta), standard errors (SE) and $P$-values for the Asian dust (AD) indicator variable, pollen concentration, interaction between $A D$ and pollen, suspended paticulate matter (SPM) and interaction between AD and SPM, by clinic in Fukuoka City, Japan. (PDF 233 kb)

Additional file 2: Table S2. Regression ${ }^{\text {a }}$ coefficients (beta), standard errors (SE) and $P$-values for suspended paticulate matter (SPM), pollen concentration, and their interaction for four clinics in Fukuoka City, Japan. (PDF 179 kb)

\section{Abbreviations}

AD: Asian Dust; Cl: Confidence intervals; RR: Relative risk; SPM: Suspended particulate matter

\section{Acknowledgments}

We thank Eiko Koto from the Japan Allergy Foundation (Kyushu Branch) for her assistance in preparing the data on airborne pollen concentration. We also thank the Fukuoka Prefecture Medical Association and the Fukuoka Prefecture Medical Center for providing the pollinosis consultation data collected by otorhinolaryngologists and ophthalmologists in Fukuoka prefecture.

\section{Funding}

This study was conducted as a part of the project entitled Development of a Seamless Chemical Assimilation System and its Application for Atmospheric Environmental Materials (SALSA), which is supported by a grant-in-aid from the Research Program on Climate Change Adaptation (RECCA) by the Ministry of Education, Culture, Sports, Science and Technology (MEXT) and the Ministry of the Environment (MOE) in Japan. The funding organizations played no role in the design of the study, in the analysis and interpretation of data, in the writing of the report, or in the decision to submit for publication.

Availability of data and materials

Please contact the corresponding author. 


\section{Authors' contribution}

SS, SK and CFSN participated in the design of the study. RK collected the clinic consultation data for pollinosis. SS and CFSN performed the statistical analysis. SS and SK drafted the manuscript and interpreted the data together with CFSN and CW. All authors have read and approved the final manuscript.

\section{Competing interests}

The authors declare that they have no competing interests.

\section{Consent for publication}

Not applicable.

\section{Ethics approval and consent to participate}

Not applicable.

\section{Author details}

'Department of Human Ecology, Graduate School of Medicine, The University of Tokyo, 7-3-1 Hongo, Bunkyo-ku, Tokyo 113-0033, Japan. ${ }^{2}$ Department of Anthropology, University of Washington, Box 353100, Seattle, WA 98195-3100, USA. ${ }^{3}$ Department of Pediatric Infectious Diseases, Institute of Tropical Medicine, Nagasaki University, 1-12-4 Sakamoto, Nagasaki City, Nagasaki 852-8523, Japan. ${ }^{4}$ Clinical Research Center, Fukuoka National Hospital, 4-39-1 Yakatabaru, Minami-ku, Fukuoka 811-1394, Japan.

\section{Received: 10 October 2016 Accepted: 21 February 2017} Published online: 04 April 2017

\section{References}

1. Chan CC, Ng HC. A case-crossover analysis of Asian dust storms and mortality in the downwind areas using 14-year data in Taipei. Sci Total Environ. 2011:410-411:47-52.

2. Kashima S, Yorifuji T, Tsuda T, Eboshida A. Asian dust and daily all-cause or cause-specific mortality in western Japan. Occup Environ Med. 2012;69:908-15.

3. Kashima S, Yorifuji T, Bae S, Honda Y, Lim YH, Hong YC. Asian dust effect on cause-specific mortality in five cities across South Korea and Japan. Atmos Environ. 2015;128:20-7.

4. Kwon HJ, Cho SH, Chun Y, Largarde F, Pershagen G. Effects of the Asian dust events on daily mortality in Seoul, Korea. Environ Res. 2002;90:1-5.

5. Neophytou AM, Yiallouros P, Coull BA, Kleanthous S, Pavlou P, Pashiardis S, Dockery DW, Koutrakis P, Laden F. Particulate matter concentrations during desert dust outbreaks and daily mortality in Nicosia, Cyprus. J Expo Sci Environ Epidemiol. 2013;23:275-80.

6. Pérez L, Tobías A, Pey J, Pérez N, Alastuey A, Sunyer J, Querol X. Effects of local and Saharan particles on cardiovascular disease mortality. Epidemiol. 2012;23:768-9

7. Sajani SZ, Miglio R, Bonasoni P, Cristofanelli P, Marinoni A, Sartini C, Goldoni CA, Girolamo GD, Lauriola P. Saharan dust and daily mortality in EmiliaRomagna (Italy). Occup Environ Med. 2011:68:446-51.

8. Hwang SS, Cho SH, Kwon HJ. Effects of the severe Asian dust events on daily mortality during the spring of 2002, in Seoul, Korea. J Prev Med Public Health. 2005;28:197-202.

9. Cheng MF, Ho SC, Chiu HF, Wu TN, Chen PS, Yang CY. Consequence of exposure to Asian dust storm events on daily pneumonia hospital admissions in Taipei, Taiwan. J Toxicol Environ Health Part A. 2008;71:1295-9.

10. Meng Z, Lu B. Dust events as a risk factor for daily hospitalization for respiratory and cardiovascular diseases in Minqin, China. Atmos Environ. 2007:41:7048-58.

11. Yang CY, Chen YS, Chiu HF, Goggins WB. Effects of Asian dust storm events on daily stroke admissions in Taipei, Taiwan. Environ Res. 2005;99:79-84.

12. Bell ML, Levy JK, Lin Z. The effect of sandstorms and air pollution on cause-specific hospital admissions in Taipei, Taiwan. Occup Environ Med. 2008;65:104-11.

13. Kanatani KT, Ito I, Al-Delaimy WK, Adachi Y, Mathews WC, Ramsdell JW, the Toyama Asian Desert Dust and Asthma Study Team. Desert dust exposure is associated with increased risk of asthma hospitalization in children. Am J Respir Crit Care Med. 2010;182:1475-81.

14. Watanabe M, Yamasaki A, Burioka N, Kurai J, Yoneda K, Yoshida A, Igishi T, Fukuoka Y, Nakamoto M, Takeuchi H, Suyama H, Tatsukawa T, Chikumi H, Matsumoto S, Sako T, Hasegawa Y, Okazaki R, Horasaki K, Shimizu E. Correlation between Asian dust storms and worsening asthma in Western Japan. Allergol Int. 2011;60:267-75.
15. Otani S, Onishi K, Mu H, Yokoyama Y, Hosoda T, Okamoto M, Kurozawa Y. The relationship between skin symptoms and allergic reactions to Asian dust. Int J Environ Res Public Health. 2012;9:4606-14.

16. Ueda K, Nitta $\mathrm{H}$, Odajima $\mathrm{H}$. The effects of weather, air pollutants, and Asian dust on hospitalization for asthma in Fukuoka. Environ Health Prevent Med. 2010:15:350-7.

17. Yang CY, Tsai S, Chang CC, Ho SC. Effects of Asian dust storm events on daily admissions for asthma in Taipei, Taiwan. Inhal Toxicol. 2005;17:817-21.

18. Yang CY. Effects of Asian dust storm events on daily clinical visits for conjunctivitis in Taipei, Taiwan. J Toxicol Environ Health Part A. 2006;69:1673-80.

19. Mimura T, Yamagami S, Fujishima H, Noma H, Kamei Y, Goto M, Kondo A, Matsubara M. Sensitization to Asian dust and allergic rhinoconjunctivitis. Environ Res. 2014;132:220-5.

20. Ogi K, Takabayashi T, Sakashita M, Susuki D, Yamada T, Manabe Y, Fujieda S. Effect of Asian sand dust on Japanese cedar pollinosis. Auris Nasus Larynx. 2014;41:518-22.

21. Otani S, Onishi K, Mu H, Kurozawa Y. The effect of Asian dust events on the daily symptoms in Yonago, Japan: a pilot study on healthy subjects. Arc Environ Occup Health. 2011;66:43-6.

22. Kamouchi M, Ueda K, Ago T, Nitta H, Kitazono T. Relationship between Asian dust and ischemic stroke a time-stratified case-crossover study. Stroke. 2012:43:3085-7.

23. Chang CC, Lee IM, Tsai SS, Yang CY. Correlation of Asian dust storm events with daily clinic visits for allergic rhinitis in Taipei, Taiwan. J Toxicol Environ Health A. 2006;69:229-35.

24. Konishi S, Ng CFS, Stickley A, Nishihata S, Shinsugi C, Ueda K, Takami A, Watanabe C. Particulate matter modifies the association between airborne pollen and daily medical consultations for pollinosis in Tokyo. Sci Total Environ. 2014:499:125-32.

25. Fukuoka Prefecture Medical Association. Information of pollen in Kyushu for 20 years (Kyushu kafun jyoho 20 nen no ayumi) 2010; p6. (in Japanese).

26. Guidelines Planning Committee of Allergic Rhinitis Consultation. Guidelines of Allergic Rhinitis Consultation. - Perennial Rhinitis and Pollinosis - 2013 version (Seventh edition) (Hana arerugi sinryo gaidorain - Tsunenseibien to kafunsho - 2013nenban (kaitei dai 7 ban)) 2013; p21. (in Japanese).

27. Kishikawa R, Sahashi N, Saitoh A, Kotoh E, Shimoda K, Shoji S, Akiyama K, Nishima S. Japanese cedar airborne pollen monitoring by Durham's and burkard samplers in Japan -estimation of the usefulness of Durham's sampler on Japanese cedar pollinosis. Global Environ Res. 2009;13:55-62.

28. Watanabe M, Noma H, Kurai J, Sano H, Mikami M, Yamamoto H, Ueda Y, Touge H, Fujii Y, Ikeda T, Tokuyasu H, Konishi T, Yamasaki A, Igishi T, Shimizu E. Effect of Asian dust on pulmonary function in adult asthma patients in western Japan: a panel study. Allergol Int. 2016;65:147-52.

29. Hara K, Homma J, Tamura K, Inoue M, Karita K, Kondo Y, Yono E. Difference in concentration trends of airborne particulate matter during rush hour on weekdays and Sundays in Tokyo, Japan. J Air Waste Manag Assoc. 2014;64:1045-53.

30. Schenker N, Gentleman JF. On judging the significance of differences by examining the overlap between confidence intervals. Am Stat. 2001; 55:182-6.

31. Onishi K, Kurosawa Y, Otani S, Yoshida A, Sugimoto N, Kurozawa Y. Atmospheric transport route determines components of Asian dust and health effects in Japan. Atmos Environ. 2012;49:94-102.

32. Choi DS, Park YK, Oh SK, Yoon HJ, Kim JC, Seo WJ, Cha SH. Distribution of airborne microorganisms in yellow sands of Korea. J Microbiol. 1997;35:1-9.

33. Griffin DW. Atmospheric movement of microorganisms in clouds of desert dust and implications for human health. CMR. 2007;20:459-77.

34. Nishihata S, Saito Y. Medical consultation dynamics in Japanese cedar pollinosis patients at an office building clinic in central Tokyo. J Otolaryngol Japan. 2002;105:751-8 (in Japanese).

35. D'Amato G, Cecchi L, Bonini S, Nunes C, Annesi-Maesano I, Behrendt H, Liccardi G, Popov T, van Cauwenberge P. Allergenic pollen and pollen allergy in Europe. Allergy. 2007;62:976-90.

36. Takahashi $Y$, Sakaguchi M, Inouye S, Miyazawa H, Imaoka K, Katagiri S. Existence of exine-free airborne allergen particles of Japanese cedar (Cryptomeria japonica) pollen. Allergy. 1991;46:588-93.

37. Nishihata S, Saito Y. Consultation patterns among Japanese cedar pollinosis subjects at an urban clinic report 2: a 20-year experience (1990-2009) in Chiyoda ward, Tokyo. Nippon Jibiinkoka Gakkai Kaiho. 2012;115:165-72 (in Japanese). 
38. Chung HY, Hsieh CJ, Tseng CC, Yiin LM. Association between the first occurrence of allergic rhinitis in preschool children and air pollution in Taiwan. Int J Environ Res Public Health. 2016;13:268.

39. Lee YL, Shaw CK, Su HJ, Lai JS, Ko YC, Huang SL, Sung FC, Guo YL. Climate, traffic-related air pollutants and allergic rhinitis prevalence in middle-school children in Taiwan. Eur Respir J. 2003;21:964-70.

Submit your next manuscript to BioMed Central and we will help you at every step:

- We accept pre-submission inquiries

- Our selector tool helps you to find the most relevant journal

- We provide round the clock customer support

- Convenient online submission

- Thorough peer review

- Inclusion in PubMed and all major indexing services

- Maximum visibility for your research

Submit your manuscript at www.biomedcentral.com/submit 